\title{
PENJERNIHAN AIR SUMUR MENUJU AIR LAYAK MINUM DENGAN METODA LAPISAN MULTI MEDIA (LMM)
}

Neneng Swesty ${ }^{*}$, Rahmiana Zein dan Zilfa

"Laboratorium Kimia Lingkungan, Jurusan Kimia FMIPA, Universitas Andalas

Corresponding Author:

Neneng Swesty

nengsweety23@gmail.com

Received: November 2018 Accepted: February 2019 Published: March 2019

Publishing services provided by Open Journal Systems

CNeneng Swesty et al. This is an open-access article distributed under the terms of the Creative Commons Attribution License, which permits unrestricted use, distribution, and reproduction in any medium, provided the original author and source are credited

\begin{abstract}
The Multi Soil layering (MSL) system is a liquid waste treatment method with the use of soil as the main medium and the organic material formed in brick and arranged in layers with a homogeneous zeolite layer. The MSL system is made of acrylic $(50 \times 15 \times 50) \mathrm{cm}$ containing a brick $(4 \times 9 \times 15) \mathrm{cm}$ and $(4 \times 5 \times 15) \mathrm{cm}$ of volcanic soil mixture as the main medium mixed with charcoal, rice husk, and iron powder (70:10:10:5)\%, permiable layer is used zeolite $(2-3) \mathrm{mm}$. The sample came from the well water of one of villager at Jati, Padang. Efficiency of SML system for aeration process on turbidity parameter with flow rate variation of 2, 4,6,8 mL/min reach 99,8 $\%$, for non aeration process efficiency of turbidity decrease $88,14 \%$. While for the flow rate of $10,20,40,80 \mathrm{~mL} / \mathrm{min}$, the efficiency of decrease for aeration at parameters $\mathrm{Mn} 66,44 \%$, nitrite 59,74 \%, nitrate 58,34\%, turbidity $54,63 \%$, while in non aeration efficiency decrease turbidity reach $44,04 \%$, Mn 47,26 \%, nitrite 49,74\%, nitrate 45,57\%. Of all efficiency values decreasing all parameters already complied drinking water quality standard according to Permenkes RI No. 492/Menkes/Per/IV/2010.
\end{abstract}

Keywords: Multi Soil layering (MSL); well water; volcanic soil; charcoal; iron powder; rice husk

\section{PENDAHULUAN}

Air merupakan kebutuhan yang sangat penting bagi manusia baik secara langsung maupun tidak langsung. Air minum merupakan kebutuhan yang sangat vital untuk kehidupan. Manusia tidak akan bertahan hidup pada jangka waktu yang lama tanpa mengkonsumsi air minum. Sedangkan air yang dikonsumsi secara langsung mempunyai persyaratan tertentu, utamanya dengan mempertimbangkan aspek kesehatan. Manusia membutuhkan air minum sebanyak 3\% dari berat badannya atau sekitar 2,5 L setiap hari. Air mempunyai bermacam-macam kandungan senyawa, tergantung dari sumbernya. Oleh karena itu air yang berasal dari sumbernya harus diperiksa terlebih dahulu untuk mengetahui apakah air tersebut memenuhi persyaratan fisika, kimia, maupun biologi [1].

Di tengah kesulitan memperoleh air bersih untuk air minum yang layak dikonsumsi, berbagai cara telah dilakukan masyarakat. Menggali sumur, sebagai sebuah alternatif yang saat ini masih banyak dilakukan warga, terutama warga pedesaan. Akan tetapi masalah pun akan datang seiring musim kemarau tiba. Air bersih pun sulit didapatkan karena sumur bisa saja akan kering. Sumur bor, salah satu cara yang banyak dilakukan warga guna memperoleh air bersih. Kita ketahui bahwa biaya membuat sumur bor tidaklah murah, sekitar 7 hingga 8 juta bahkan bisa lebih sesuai 
kedalamannya. Biaya semahal ini tidak sebanding dengan kualitas air yang diperoleh. Jika dilihat dari jumlah air, memang banyak dan melimpah, tetapi kebanyakan kualitas air dari sumur bor cenderung keruh dan berminyak. Dampak dari hal ini, masyarakat harus membuat filter air secara manual guna menyaring air kemudian memasak air tersebut agar air aman untuk minum.

Banyak cara untuk mengelola air yakni filtrasi, koagulasi, pengendapan, penggunaan disinfektan, kontrol bau dan lain - lainnya. Namun pada tahun 1990-an telah ditemukan teknik/metode untuk menjernihkan air yang dikenal dengan sistem Lapisan Multi Media (LMM). Salah satu metode pengolahan yang memanfaatkan media tanah adalah Lapisan Multi Media (LMM), yaitu media tanah sebagai media utama disusun dalam sebuah konstruksi susunan batu bata yang terdiri atas lapisan campuran tanah dengan $10-35 \%$ partikel besi, bahan organik dan lapisan zeolit ${ }^{[2]}$.

Sistem Lapisan Multi Media (LMM) mempunyai beberapa kelebihan, antara lain mampu mereduksi nilai BOD, COD, TSS, warna, dan menghilangkan bau secara simultan, mempunyai kemampuan yang tinggi untuk menerima dan menyerap air yang dialirkan ke sistem, 1000-4000 Lm$^{-2} \mathrm{~d}^{-1}$ sedangkan tanah konvensional 10-40 $\mathrm{Lm}^{-2} \mathrm{~d}^{-1}$, dapat mencegah terjadinya penyumbatan dan tidak membutuhkan lahan yang luas seperti kolam treatment ${ }^{[3-4]}$.

Untuk mengatasi permasalahan air, dapat dilakukan penyerapan dengan metoda LMM (Lapisan Multi Media). Pada penelitian ini dilakukan untuk melihat kemampuan LMM dengan menggunakan material seperti tanah vulkanik dari kaki gunung merapi, zeolit, arang tempurung kelapa, serbuk besi dan sekam padi dalam penjernihan air sumur yang keruh dan kuning untuk layak minum. Sesuai dengan standar baku mutu kesehatan yang tercantum dalam Peraturan Menteri Kesehatan RI Nomor 492/MENKES/PER/IV/2010.

\section{METODOLOGI PENELITIAN}

\section{Bahan Kimia}

Bahan-bahan yang digunakan pada penelitian ini adalah $\mathrm{H}_{2} \mathrm{SO}_{4} 98 \%$, kalium hidrogen ftalat $\left(\mathrm{KHC}_{8} \mathrm{H}_{4} \mathrm{O}_{4}\right)$, kalium dihidrogen fosfat $\left(\mathrm{KH}_{2} \mathrm{PO}_{4}\right)$, dinatrium hidrogen fosfat $\left(\mathrm{Na}_{2} \mathrm{HPO}_{4}\right)$, natrium hidrogen karbonat $\left(\mathrm{NaHCO}_{3}\right)$, natrium karbonat $\left(\mathrm{Na}_{2} \mathrm{CO}_{3}\right)$, hidrazin sulfat $\left(\mathrm{NH}_{2}\right)_{2} . \mathrm{H}_{2} \mathrm{SO}_{4}$, heksametilen tetraamin $\left(\mathrm{CH}_{2}\right)_{6}\left(\mathrm{NH}_{2}\right)_{4}$, ferro ammonium sulfat, indikator ferroin, perak sulfat $\left(\mathrm{Ag}_{2} \mathrm{SO}_{4}\right)$, $\mathrm{HCl}$ pekat, $\mathrm{MnSO}_{4} .4 \mathrm{H}_{2} \mathrm{O}, \mathrm{HNO}_{3}$ pa, $\mathrm{KMnO}_{4}$, natrium oksalat $\left(\mathrm{Na}_{2} \mathrm{C}_{2} \mathrm{O}_{4}\right), \mathrm{FeSO}_{4} .7 \mathrm{H}_{2} \mathrm{O}, 1-10$ fenantrolin monohidrat, $\mathrm{NaNO}_{2}, \mathrm{NaCl}$, asam sulfanilat, asam asetat $\left(\mathrm{CH}_{3} \mathrm{COOH}\right)$, naftil etilendiamin dihidroklorida, brusin sulfat, Akuades.

\section{Peralatan}

Alat-alat yang digunakan dalam penelitian ini adalah sistem Lapisan Multi Media (LMM), pH Meter (Trans Instruments), stopwatch, neraca analitik (AA-200, Denver Instrument Company), aerator (Amara, AA-350), pompa vakum (Front Lab FP 300), Spektrofotometer Serapan Atom (Rayleight, WFX-320), Spektrofotometer UV - Vis (UV-2600 Shimadzu), serta alat-alat gelas

\section{Prosedur Penelitian}

\section{Reaktor LMM}

Reaktor LMM terbuat dari bahan akrilik berbentuk segiempat dengan dimensi (50 x $15 \mathrm{x}$ 50) $\mathrm{cm}$. Media dalam reaktor terdiri dari campuran tanah vulkanik (kaki Gunung Merapi Kota Madya Padang Panjang), arang halus, serbuk besi dan sekam padi dengan perbandingan (75: 10 : 10 : 5)\%, yang dibungkus dengan karung goni kemudian disusun dalam box akrilik seperti susunan batu bata diselingi dengan zeolit antara bata tersebut setebal $4 \mathrm{~cm}$ (Gambar 1). 


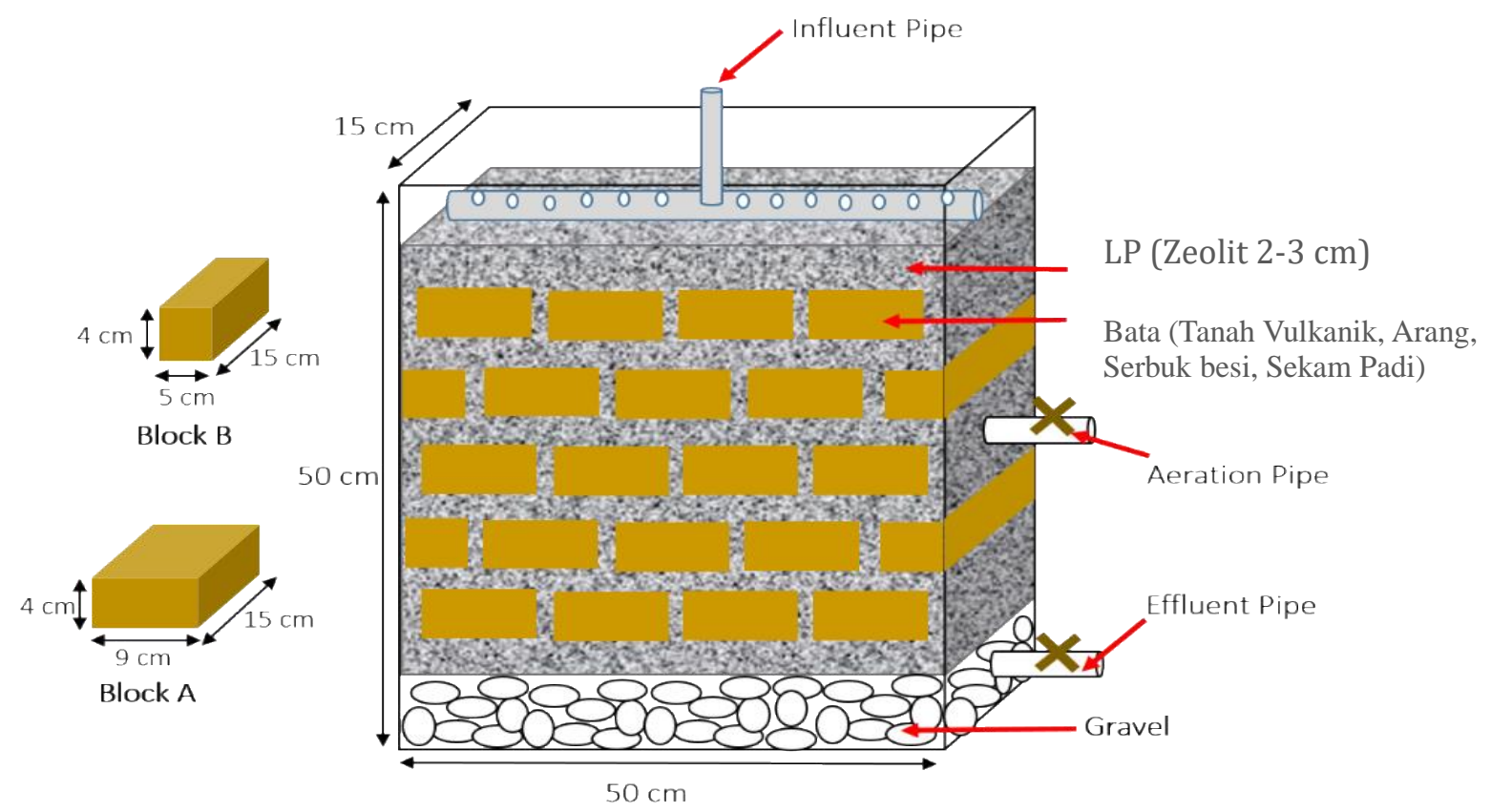

Gambar 1. Desain Reaktor LMM

\section{Perlakuan Terhadap Sampel}

Air sumur yang telah diambil dilakukan terlebih dahulu penganalisaan kualitas airnya dengan parameter fisika seperti bau, kekeruhan dan beberapa parameter kimia seperti $\mathrm{pH}$, nitrit, nitrat, Mn dalam air sumur tersebut. Untuk memprediksikan kemampuan dari sistem LMM ini maka dilakukan penganalisaan air sumur sebelum dan sesudah pada proses aerasi dan non aerasi dengan menvariasikan kecepatan alirnya.

\section{Metoda Analisis}

Semua analisis parameter $\mathrm{pH}$, kekeruhan, nitrit, nitrat, dan Mn, sesuai Standar Nasional Indonesia (SNI). Penentuan $\mathrm{pH}$ (SNI 066989.11-2004), Penentuan Kekeruhan (SNI 066989.25-2005), penentuan kadar nitrit (SNI-066989.9-2004), penentuan nitrat (SNI 06-24801991), penentuan logam mangan (SNI 6989.52009).

\section{Penentuan pH (SNI 06-6989.11-2004)}

$\mathrm{pH}$-meter dikalibrasi dengan menggunakan larutan penyangga setiap kali akan melakukan pengukuran, dilakukan pada suhu kamar.
Elektroda dikeringkan dengan kertas tisu selanjutnya elektroda dibilas dengan air suling, kemudian elektroda dibilas dengan sampel uji. Elektroda dicelupkan ke dalam contoh uji sampai pH-meter menunjukkan pembacaan yang tetap. Selanjutnya dicatat hasil skala yang ditunjukkan oleh tampilan $\mathrm{pH}$-meter.

\section{Penentuan Kekeruhan (SNI 06-6989.25-2005)}

Pembuatan Larutan Standar Kekeruhan (Formazin) Larutan I: Dilarutkan 1,0003 gram hidrazin sulfat $\left(\mathrm{NH}_{2}\right)_{2} \cdot \mathrm{H}_{2} \mathrm{SO}_{4}$ dalam labu ukur $100 \mathrm{~mL}$. Larutan II : Larutkan 10,0002 gram heksametilen tetraamin $\left(\mathrm{CH}_{2}\right)_{6}\left(\mathrm{NH}_{2}\right)_{4}$ dalam labu ukur $100 \mathrm{~mL}$. Campurkan $5 \mathrm{~mL}$ larutan I dan II di dalam labu ukur $100 \mathrm{~mL}$. Larutan didiamkan selama 24 jam pada temperatur $25^{\circ} \mathrm{C}$ kemudian diencerkan menjadi $100 \mathrm{~mL}$. Kekeruhan tersuspensi tersebut adalah 400 NTU. Larutan stock tersebut harus terus dijaga agar tetap dalam keadaan segar. Pipet $10 \mathrm{~mL}$ larutan stock, encerkan dalam labu $100 \mathrm{~mL}$, sehingga larutan tersuspensi 40 NTU. Pipet larutan tersebut $(0,625 ; 1,25 ; 2,5 ; 4,375 ; 7,5)$ $\mathrm{mL}$ encerkan dalam labu $25 \mathrm{~mL}$ (larutan 
standar formazin dengan variasi konsentrasi (1 ; 2 ; 4 ; ; 12) NTU.

\section{Pengukuran Kekeruhan Dengan Spektrofotometer}

Spektrofotometer dihubungkan dengan sumber arus, alat dihidupkan dan distabilkan selama \pm 15 menit. Atur panjang gelombang untuk kekeruhan $420 \mathrm{~nm}$. Masukkan kuvet yg telah berisi larutan blanko. Nilai absorban di atur 0,000. Ukur deret larutan standar kekeruhan, Lakukan pengukuran yang sama terhadap sampel.

\section{Penentuan Kadar Nitrit (SNI-06-6989.9-2004)}

\section{Pembuatan Larutan Standar}

Larutan standar nitrit dengan konsentrasi $(0,02$ ; 0,$05 ; 0,1 ; 0,2 ; 0,3) \mathrm{mg} / \mathrm{L}$ dari larutan standar nitrit $10 \mathrm{mg} / \mathrm{L}$, pipet $5 \mathrm{~mL}$ masing-masing larutan standar nitrit dan masukkan ke dalam botol film, kemudian tambahkan $1 \mathrm{~mL}$ reagen Saltzman, aduk dan biarkan 30 menit (sampai terbentuk warna pink). Ukur absorbannya dengan spektrofotometer pada panjang gelombang $550 \mathrm{~nm}$.

\section{Pembuatan Larutan Sampel}

$5 \mathrm{~mL}$ sampel dimasukkan ke dalam botol film, kemudian tambahkan $1 \mathrm{~mL}$ reagen Saltzman, aduk dan biarkan 30 menit. Ukur absorbannya dengan spektofotometer pada panjang gelombang $550 \mathrm{~nm}$.

\section{Pengukuran Nitrit dengan Spektrofotometer}

Spektrofotometer dihubungkan dengan sumber arus, lalu alat dihidupkan dan distabilkan selama \pm 15 menit. Atur panjang gelombang untuk kekeruhan $550 \mathrm{~nm}$, kemudian masukkan kuvet yang telah berisi larutan blanko, lalu nilai absorban di atur 0,000. Ukur deret larutan standar nitrit dan lakukan pengukuran yang sama terhadap sampel.

\section{Penentuan Nitrat (SNI 06-2480-1991)}

a)10 mL contoh air yang jernih (bila keruh harus disaring) ditambahkan $2 \mathrm{~mL}$ larutan $\mathrm{NaCl}, 10 \mathrm{~mL}$ larutan $\mathrm{H}_{2} \mathrm{SO}_{4}$ dan 0,5 mL larutan brusin- sulfanilat. b) Kemudian dipanaskan di atas penangas air $\left(95^{\circ} \mathrm{C}\right.$ selama 20 menit. Tambahkan akuades hingga volume $25 \mathrm{~mL}$. c) Setelah ingin ukur intensitasnya dengan spektrofotometer pada panjang gelombang 420 nm.

\section{Pembuatan kurva kalibrasi}

Dibuat larutan standar Nitrat 0,$0 ; 0,1 ; 3,0 ; 6,0$; 10,$0 ; 15,0$ dan 20,0 ppm, dengan cara mengencerkan larutan standar nitrat 100 ppm. Dilakukan prosedur yang sama seperti terhadap contoh air pada $10 \mathrm{~mL}$ tiap larutan standar. Buat kurva kalibrasi antara absorban vs konsentrasi (ppm). Tentukan slope (ppm/unit absorban)

Perhitungan :

Konsentrasi Nitrat $=\mathrm{A} \times \mathrm{S}=\ldots \ldots$ ppm

Keterangan :

$\mathrm{A}=$ absorban sampel $; \mathrm{B}=$ kemiringan kurva

kalibrasi ( ppm / unit absorban )

\section{Penentuan Logam Mangan (SNI 6989.5-2009)}

\section{Persiapan contoh uji Mangan terlarut}

Siapkan contoh uji yang telah disaring dengan saringan membrane berpori 0,45 $\mu \mathrm{m}$ dan diawetkan. Contoh uji siap diukur.

\section{Persiapan contoh uji Mangan total}

Siapkan contoh uji untuk pengujian mangan total, dengan tahapan sebagai berikut : a) contoh uji dihomogenkan dengan memipet 50 $\mathrm{mL}$ contoh uji ke dalam gelas piala $100 \mathrm{~mL}$ atau Erlenmeyer $100 \mathrm{~mL}$; b) $5 \mathrm{~mL} \mathrm{HNO}_{3}$ pekat ditambahkan, bila menggunakan gelas piala, tutup dengan kaca arloji dan bila dengan Erlenmeyer gunakan corong sebagai penutup; c) larutan dipanaskan dengan pengaturan suhu stabil sampai sisa volumenya $15 \mathrm{ml}-20 \mathrm{~mL}$; d) jika destruksi belum sempurna (tidak jernih) dilakukan penambahan $5 \mathrm{~mL} \mathrm{HNO}_{3}$ pekat, kemudian gelas piala ditutup dengan kaca arloji atau tutup Erlenmeyer dengan corong dan dipanaskan lagi (tidak mendidih). Proses ini dilakukan secara berulang sampai semua logam larut, yang terlihat dari warna endapan dalam contoh uji menjadi agak putih atau contoh uji menjadi jernih; e) Kaca arloji dibilas dan air bilasannya dimasukkan ke dalam gelas piala; f) Contoh uji dipindahkan ke dalam labu ukur $50 \mathrm{~mL}$ (disaring bila perlu) dan ditambahkan air bebas mineral sampai tepat 
tanda tera dan dihomogenkan; CATATAN dilakukan penambahan matrix modifier (larutan kalsium) dan atau atasi gangguan pengukuran sesuai dengan SSA yang diguanakan; g) contoh uji siap diukur serapannya.

\section{Pembuatan larutan Mangan $100 \mathrm{mg} \mathrm{Mn/L}$}

a) Sebanyak $\pm 0,10003 \mathrm{~g}$ logam mangan ditimbang, dimasukkan ke dalam labu ukur $1000 \mathrm{~mL}$; b) ditambahkan campuran $10 \mathrm{~mL} \mathrm{HCl}$ pekat dan $1 \mathrm{~mL} \mathrm{HNO}_{3}$ pekat hingga larut; c) ditambahkan air bebas mineral hingga tepat tanda tera, lalu dihomogenksan; $(\approx 100 \mathrm{mg}$ $\mathrm{Mn} / \mathrm{L})$; d) dihitung kembali kadar sesungguhnya berdasarkan hasil penimbangan.

\section{Pembuatan larutan Mangan $10 \mathrm{mg} \mathrm{Mn} / \mathrm{L}$}

a) Sebanyak $10 \mathrm{~mL}$ larutan standar dipipet dan mangan 100 mg/L Mn, dimasukkan ke dalam labu ukur $100 \mathrm{~mL}$; b) ditepatkan dengan larutan pengencer sampai tanda tera dan dihomogenkan.

\section{Pengukuran contoh uji}

Uji kadar mangan dengan tahapan sebagai berikut :

Contoh uji injeksikan ke dalam SSA nyala lalu sarapannya diukur pada panjang gelombang 279,5 nm. Dan apabila diperlukan, dilakukan pengenceran.

\section{Perhitungan}

Kadar logam mangan (Mn)

$\operatorname{Mn}(\mathrm{mg} / \mathrm{L})=\mathrm{C} \times \mathrm{fp}(1)$

Keterangan :

$\mathrm{C}$ adalah kadar yang didapat hasil pengukuran (mg/L)

fp adalah faktor pengeneran

\section{HASIL DAN DISKUSI}

Hasil Analisis Air Sumur Setelah Perlakuan Aerasi dan Non Aerasi pada sistem LMM.

Berdasarkan hasil analisis air sumur yang telah diperlakukan menggunakan sistem LMM yang dicampurkan sekam padi dengan perlakuan aerasi dan non aerasi (Tabel 1) hasil analisis $\mathrm{pH}$, bau, Nitrat, Nitrit sudah memenuhi standar air minum. Tapi hasil analisis kekeruhan dengan metoda aerasi dan non aerasi pada laju alir 10, 20, 40, $80 \mathrm{~mL} / \mathrm{menit}$ masih belum memenuhi standar baku mutu air minum namun setelah dilakukan percobaan dengan memperkecil kecepatan alir dari 2, 4, 6, $8 \mathrm{~mL} / \mathrm{menit}$ (Tabel 2) nilai kekeruhan sudah berada pada nilai ambang batas Permenkes RI No. 492/Menkes/Per/IV/2010 yaitu 5 NTU.

\section{Analisis pH}

$\mathrm{pH}$ merupakan konsentrasi ion Hidrogen $\left(\mathrm{H}^{+}\right)$ dalam suatu cairan. $\mathrm{pH}$ juga merupakan parameter kimia yang penting dalam analisis air. Organisme sangat sensitif terhadap perubahan ion hidrogen. Pada proses penjernihan air dan air limbah, $\mathrm{pH}$ merupakan indikator untuk meningkatkan efisiensi proses penjernihan.

Berdasarkan nilai $\mathrm{pH}$ air sumur (Gambar 2) sebelum dilewatkan ke sistem LMM adalah sebesar 6,7. Nilai $\mathrm{pH}$ ini berada antara nilai baku mutu air minum Permenkes RI No. 492/Menkes/Per/IV/2010 yaitu 6,5-8,5. Artinya $\mathrm{pH}$ pada air sumur salah satu warga Jati Padang telah memenuhi standar baku mutu air minum. Dari hasil pengukuran $\mathrm{pH}$ air sumur yang sudah dilewatkan pada sistem LMM dengan proses aerasi dan non aerasi nilai $\mathrm{pH}$ naik dari 6,7 menjadi 7,2-7,7. Disini menunjukkan bahwa konsentrasi ion hidroksil $(\mathrm{OH})$ lebih tinggi dari pada konsentrasi ion hidrogen. Hal ini disebabkan karena bertambahnya ion $\mathrm{OH}^{-}$dari proses denitrifikasi dari bakteri Nitrobacter ${ }^{[4]}$.

\section{Analisis Kekeruhan}

Hasil analisis kekeruhan air sumur setelah melewati sistem LMM pada proses aerasi dan non aerasi mengalami penurunan di setiap variasi laju alir $(10,20,40,80) \mathrm{mL} /$ menit dari nilai awal kekeruhan 27,455 NTU (Gambar 3a). Tapi nilai penurunan kekeruhannya masih diatas nilai baku mutu air minum. Maka dicoba lagi untuk mengalirkan air sumur ke dalam alat LMM dengan memperkecil laju alirnya menjadi $(2,4,6,8) \mathrm{mL} /$ menit pada proses aerasi dan non aerasi. 


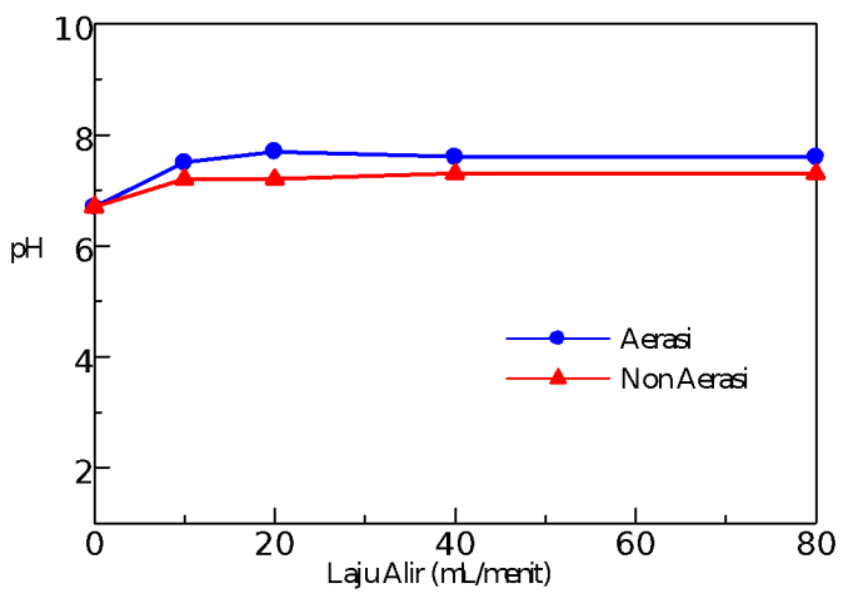

Gambar 2. Nilai pH sebelum dan setelah perlakuan dengan sistem LMM pada proses aerasi dan non aerasi.

Didapatkan hasil yang sudah berada dibawah nilai standar baku mutu air minum Permenkes RI No. 492/Menkes/Per/2010. Penurunan efisiensi kekeruhan terjadi setiap variasi laju alir $(2,4,6,8) \mathrm{mL} /$ menit (Gambar 3b) pada proses aerasi masing-masing 95,88 \%, 92,78 \%, $87,11 \%, 84,02 \%$ dan untuk non aerasi $88,14 \%$, $86,08 \%, 79,89 \%, 75,26 \%$. Dari nilai efisiensi tersebut, laju alir $2 \mathrm{~mL} / \mathrm{menit}$ yang baik pada proses aerasi maupun non aerasi dan terjadi penurunan saat meningkatnya laju alir. Kekeruhan pada air sumur yang diberlakukan dengan sistem LMM tersorpsi pada permukaan lapisan zeolit dan balok-balok tanah. Zeolit memiliki pori-pori besar yang menyerap bahan - bahan organik, sehingga zeolit dapat berfungsi sebagai adsorben [8]. Berdasarkan penelitian yang di lakukan Munaf, bahwa sekam padi dapat mengadsorpsi logam berat pada limbah cair [9]. Selain itu, mikroorganisme yang ada dalam tanah juga dapat membantu menguraikan bahan-bahan organik sehingga di dalam sistem LMM ini tidak terjadi penyumbatan.

\section{Analisis Nitrit}

Nitrit Merupakan bentuk antara oksidasi ammonia ke nitrat atau reduksi nitrat ke ammonia. Nitrit dapat masuk keperairan melalui air limbah industri. Nitrit dapat mengikat besi dari hemoglobin yang membentuk methemoglobinemia di dalam tubuh. Konsentrasi nitrit air sumur setelah melewati sistem LMM mengalami penurunan pada setiap laju alir 10, 20, 40, $80 \mathrm{~mL} / \mathrm{menit}$, seperti yang terlihat pada Gambar 4. Nilai konsentrasi Nitrit ini tidak melebihi batas baku mutu air minum menurut Permenkes RI No.492/Menkes/Per/IV/2010 yaitu 3 mg/L.

Penurunan konsentrasi nitrit yang terdeteksi pada semua variasi laju alir menunjukkan adanya proses nitrifikasi berlangsung dalam kondisi aerobik. Pada kondisi itu nitrit di oksidasi oleh bakteri Nitrosomonas menjadi nitrat, dan kemudian nitrit dalam kondisi anaerob dapat direduksi menjadi nitrogen oleh bakteri anaerob fakultatif seperti Denitrobacilus dan Nitosococcus. Di dalam sistem LMM, blok campuran tanah ada sekam padi dan arang, yang merupakan sumber nutrisi bakteri. Sehingga bakteri-bakteri ini bekerja dengan baik pada proses denitrifikasi dalam sistem LMM. Sifat nitrit yang tidak stabil dilingkungan, akan mudah berubah menjadi nitrat dalam air sumur yang diolah, dan juga dimungkinkan bahwa total amoniak yang terurai menjadi nitrit dalam proses nitrifikasi sedikit jumlahnya, sehingga nitrit yang dihasilkan menjadi sedikit ${ }^{22]}$. 


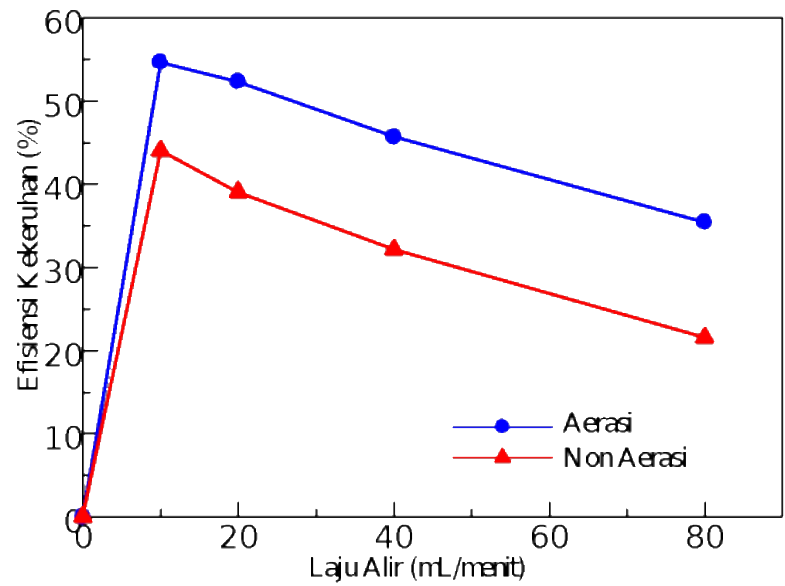

(a)

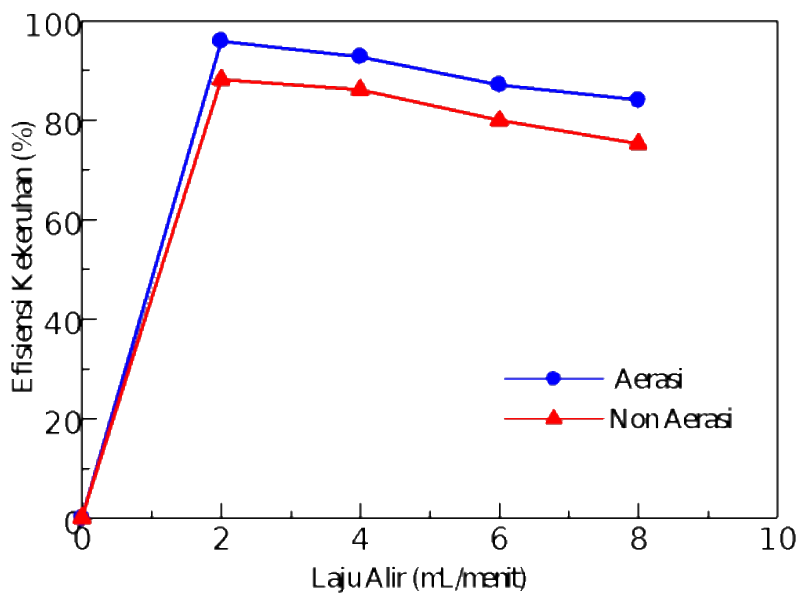

(b)

Gambar 3. Grafik efisiensi kekeruhan (a) Efisiensi penurunan kadar kekeruhan pada metoda LMM dengan proses aerasi dan non aerasi pada laju alir $(10,20,40,80) \mathrm{mL} /$ menit (b) Efisiensi penurunan kadar kekeruhan pada metoda LMM dengan proses aerasi dan non aerasi pada laju alir $(2,4,6,8)$ $\mathrm{mL} / \mathrm{menit}$.

\section{Analisis Nitrat}

Nitrat biasanya ada di air permukaan dalam konsentrasi kecil, dan kemungkinan mencapai konsentrasi tinggi pada air tanah. Adanya $\mathrm{NO}_{3}$ dalam air adalah berkaitan erat dengan siklus Nitrogen dalam alam. Dalam siklus tersebut dapat diketahui bahwa nitrat dapat terjadi baik dari $\mathrm{N}_{2}$ atmosfir maupun dari pupuk-pupuk yang digunakan dan dari oksidasi $\mathrm{NO}_{2}^{-}$oleh bakteri dari kelompok Nitrobacter. Nitrat yang terbentuk dari proses-proses tersebut adalah merupakan pupuk bagi tanaman. Nitrat yang berlebihan dari yang dibutuhkan oleh kehidupan tanaman terbawa oleh air yang merembes melalui tanah, sebab tanah tidak mempunyai kemampuan untuk menahannya. Ini yang mengakibatkan terdapatnya konsentrasi nitrat yang relatif tinggi pada air tanah. Dalam jumlah yang berlebihan dalam air dapat menimbulkan kelainan pada bayi yang disebut inflantile methomolobinemia. Nitrat adalah unsur penting dalam proses fotosintesis tanaman air [10]. 
Tabel 1. Pengaruh laju alir terhadap parameter pada proses aerasi dan non aerasi

\begin{tabular}{|c|c|c|c|c|c|c|c|c|c|c|c|}
\hline \multirow{2}{*}{ Parameter } & \multirow{2}{*}{ Satuan } & \multirow{2}{*}{$\begin{array}{l}\text { Air Sumur } \\
\text { Sebelum } \\
\text { Perlakuan }\end{array}$} & \multicolumn{4}{|c|}{$\begin{array}{c}\text { Air Sumur Setelah Perlakuan Aerasi } \\
\text { dengan Variasi Laju Alir }\end{array}$} & \multicolumn{4}{|c|}{$\begin{array}{l}\text { Air Sumur Setelah Perlakuan Non } \\
\text { Aerasi dengan Variasi Laju Alir }\end{array}$} & \multirow[b]{2}{*}{$\begin{array}{c}\text { Permenkes RI No. } \\
\text { 492/Menkes/Per/IV/2010 }\end{array}$} \\
\hline & & & $\begin{array}{c}2 \\
\mathrm{~mL} / \mathrm{mnt}\end{array}$ & $\begin{array}{c}4 \\
\mathrm{~mL} / \mathrm{mnt}\end{array}$ & $\begin{array}{c}6 \\
\mathrm{~mL} / \mathrm{mnt}\end{array}$ & $\begin{array}{c}8 \\
\mathrm{~mL} / \mathrm{mnt}\end{array}$ & $\begin{array}{c}2 \\
\mathrm{~mL} / \mathrm{mnt}\end{array}$ & $\begin{array}{c}4 \\
\mathrm{~mL} / \mathrm{mnt}\end{array}$ & $\begin{array}{c}6 \\
\mathrm{~mL} / \mathrm{mnt}\end{array}$ & $\begin{array}{c}8 \\
\mathrm{~mL} / \mathrm{mnt}\end{array}$ & \\
\hline Kekeruhan & NTU & 17.636 & 0.727 & 1.273 & 2.273 & 2.818 & 2.091 & 2.455 & 3.545 & 4.364 & 5 \\
\hline
\end{tabular}

Tabel 2. Pengaruh laju alir terhadap parameter kekeruhan pada proses aerasi dan non aerasi dengan memperkecil laju alir

\begin{tabular}{|c|c|c|c|c|c|c|c|c|c|c|c|}
\hline \multirow{2}{*}{ Parameter } & \multirow{2}{*}{ Satuan } & \multirow{2}{*}{$\begin{array}{l}\text { Air Sumur } \\
\text { Sebelum } \\
\text { Perlakuan }\end{array}$} & \multicolumn{4}{|c|}{$\begin{array}{c}\text { Air Sumur Setelah Perlakuan aerasi } \\
\text { dengan Variasi Laju Alir }\end{array}$} & \multicolumn{4}{|c|}{$\begin{array}{c}\text { Air Sumur Setelah Perlakuan non aerasi } \\
\text { dengan Variasi Laju Alir }\end{array}$} & \multirow[b]{2}{*}{$\begin{array}{c}\text { Permenkes RI No. } \\
\text { 492/Menkes/Per/IV/2010 }\end{array}$} \\
\hline & & & $\begin{array}{c}10 \\
\mathrm{~mL} / \mathrm{mnt}\end{array}$ & $\begin{array}{c}20 \\
\mathrm{~mL} / \mathrm{mnt}\end{array}$ & $\begin{array}{c}40 \\
\mathrm{~mL} / \mathrm{mnt}\end{array}$ & $\begin{array}{c}80 \\
\mathrm{~mL} / \mathrm{mnt}\end{array}$ & $\begin{array}{c}10 \\
\mathrm{~mL} / \mathrm{mnt}\end{array}$ & $\begin{array}{c}20 \\
\mathrm{~mL} / \mathrm{mnt}\end{array}$ & $\begin{array}{c}40 \\
\mathrm{~mL} / \mathrm{mnt}\end{array}$ & $\begin{array}{c}80 \\
\mathrm{~mL} / \mathrm{mnt}\end{array}$ & \\
\hline $\mathrm{pH}$ & - & 6,7 & 7,5 & 7,7 & 7,6 & 7,6 & 7,2 & 7,2 & 7,3 & 7,3 & $6.5-8.5$ \\
\hline \multirow[t]{2}{*}{ Bau } & - & Tidak Berbau & Tidak & Tidak & Tidak & Tidak & Tidak & Tidak & Tidak & Tidak & Tidak Berbau \\
\hline & & & Berbau & Berbau & Berbau & Berbau & Berbau & Berbau & Berbau & Berbau & \\
\hline Kekeruhan & NTU & 27,455 & 12,455 & 13,091 & 14,909 & 17,727 & 15,364 & 16,727 & 18,636 & 21,545 & 5 \\
\hline Nitrit & $\mathrm{mg} / \mathrm{L}$ & 0,39 & 0,157 & 0,206 & 0,238 & 0,243 & 0,196 & 0,233 & 0,270 & 0,312 & 3 \\
\hline Nitrat & $\mathrm{mg} / \mathrm{L}$ & 4,25 & 1,771 & 1,979 & 2,375 & 2,563 & 2,313 & 2,729 & 2,792 & 3,250 & 50 \\
\hline $\mathrm{Mn}$ & $\mathrm{mg} / \mathrm{L}$ & 0,146 & 0,049 & 0,065 & 0,075 & 0,080 & 0,077 & 0,084 & 0,088 & 0,097 & 0.4 \\
\hline
\end{tabular}




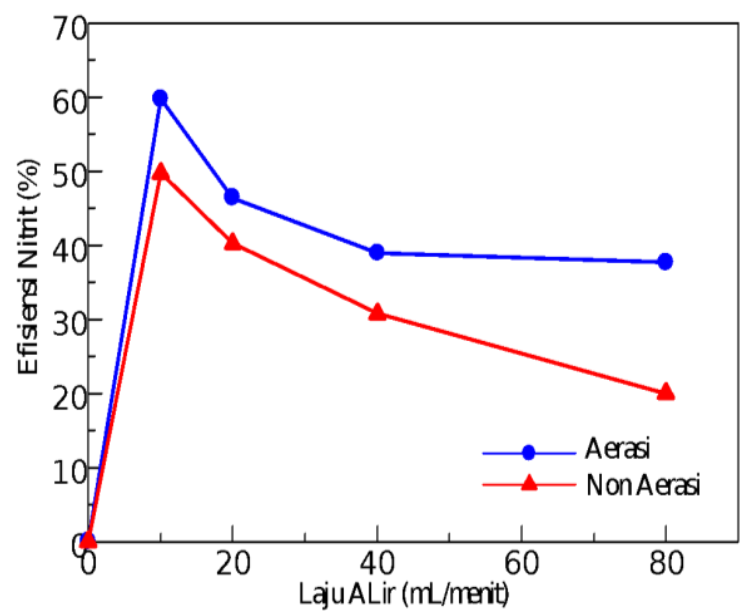

Gambar 4. Grafik Efisiensi penurunan kadar nitrit pada proses aerasi dan non aerasi

\section{Analisis Nitrat}

Nitrat biasanya ada di air permukaan dalam konsentrasi kecil, dan kemungkinan mencapai konsentrasi tinggi pada air tanah. Adanya $\mathrm{NO}_{3}$ dalam air adalah berkaitan erat dengan siklus Nitrogen dalam alam. Dalam siklus tersebut dapat diketahui bahwa nitrat dapat terjadi baik dari $\mathrm{N}_{2}$ atmosfir maupun dari pupuk-pupuk yang digunakan dan dari oksidasi $\mathrm{NO}_{2}^{-}$oleh bakteri dari kelompok Nitrobacter. Nitrat yang terbentuk dari proses-proses tersebut adalah merupakan pupuk bagi tanaman. Nitrat yang berlebihan dari yang dibutuhkan oleh kehidupan tanaman terbawa oleh air yang merembes melalui tanah, sebab tanah tidak mempunyai kemampuan untuk menahannya. Ini yang mengakibatkan terdapatnya konsentrasi nitrat yang relatif tinggi pada air tanah. Dalam jumlah yang berlebihan dalam air dapat menimbulkan kelainan pada bayi yang disebut inflantile methomolobinemia. Nitrat adalah unsur penting dalam proses fotosintesis tanaman air ${ }^{[10] .}$

Pada Gambar 5 didapatkan kadar nitrat sebelum dan sesudah dialirkan ke alat LMM sudah berada pada nilai baku mutu air minum Permenkes RI No. 492/Menkes/Per/IV/2010 yaitu $50 \mathrm{mg} / \mathrm{L}$.

\section{Analisis Mn}

Endapan $\mathrm{MnO}_{2}$ akan memberikan noda-noda pada bahan/benda-benda yang berwarna putih. Adanya unsur ini dapat menimbulkan bau dan rasa pada minuman. Konsentrasi Mn yang lebih besar dari $0,3 \mathrm{mg} / \mathrm{L}$, dapat menyebabkan rasa yang aneh pada minuman dan meninggalkan warna kecoklatan pada cucian, dan dapat juga menyebabkan kerusakan hati.

Mangan pada air sumur setelah melewati sistem LMM mengalami penurunan setiap variasi laju alir $(10,20,40,80) \mathrm{mL} /$ menit (Gambar 6) dengan efisiensi aerasi masingmasing $66.44 \%, 55.48 \%, 48.63 \%, 45.21 \%$ dan untuk non aerasi masing-masing $47.26 \%, 42.47$ $\%, 39.73 \%, 33.56 \%$.

Nilai kadar Mn yang didapatkan juga sudah memenuhi nilai baku mutu standar air minum Permenkes RI No.492/Menkes/Per/IV/2010 yaitu $0,4 \mathrm{mg} / \mathrm{L}$. Bila dibandingkan tingkat efisiensi penurunan mangan pada proses aerasi dan non aerasi, maka yang terbaik adalah pada proses aerasi. Hal ini disebabkan pada proses aerasi, mensuplai udara kedalam sistem LMM. Mengakibatkan keberadaan ion mangan yang terlarut dalam air sumur mengalami oksidasi membentuk mangan oksida yang memiliki valensi yang tinggi sehingga keberadaaan ion mangan yang terlarut dalam air sumur menjadi berkurang. 


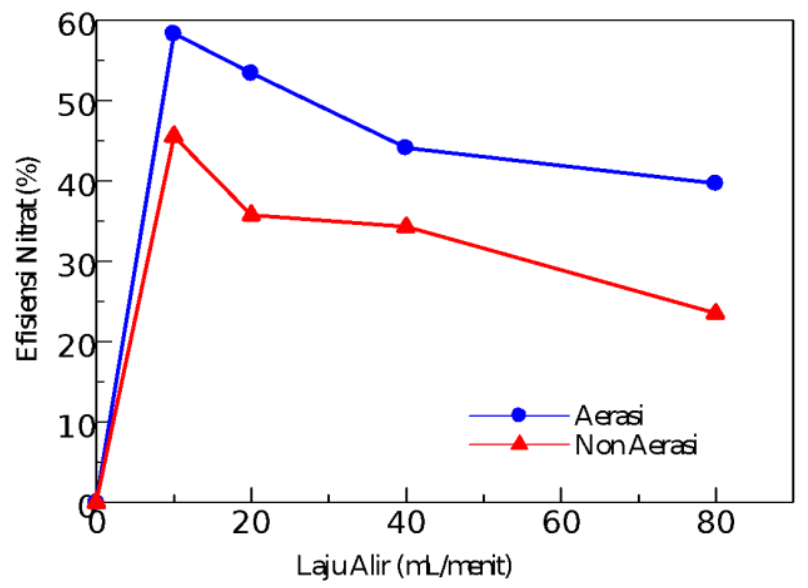

Gambar 5. Grafik Efisiensi penurunan kadar nitrat pada proses aerasi dan non aerasi

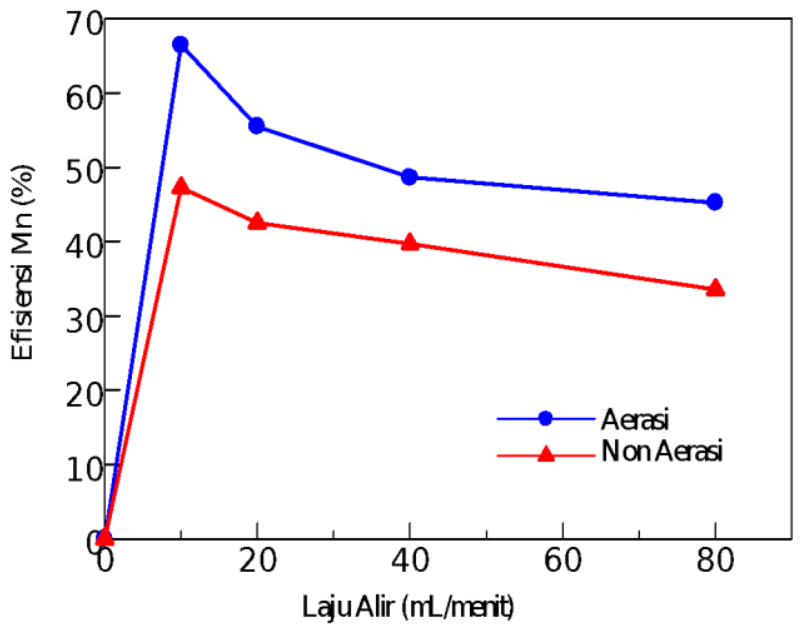

Gambar 6. Grafik Efisiensi penurunan kadar Mn pada proses aerasi dan non aerasi

\section{KESIMPULAN}

Berdasarkan baku mutu air minum menurut Permenkes RI No. 492/Menkes/Per/IV/2010, air sumur salah satu warga jati Padang sebelum melewati sisiem LMM parameter kekeruhan belum memenuhi standar untuk air minum layak konsumsi. Efisiensi sistem LMM yang dicampur dengan sekam padi dalam pengolahan air sumur, untuk proses aerasi pada parameter kekeruhan dengan variasi laju alir 2, 4, 6, 8 mL/menit mencapai 99,88\%, untuk proses non aerasi efisiensi penurunan kekeruhan 88,14\%. Sedangkan untuk variasi laju alir 10, 20, 40, $80 \mathrm{~mL} /$ menit efisiensi penurunan untuk aerasi pada parameter $\mathrm{Mn}$ $66,44 \%$, nitrit 59,74 \%, nitrat 58,34\%, kekeruhan 54,63\%, sedangkan pada proses non aerasi efisiensi penurunan kekeruhan mencapai 44,04\%, Mn 47,26 \%, nitrit 49,74\%, nitrat $45,57 \%$. Dari semua nilai efisiensi penurunan dari semua parameter sudah memenuhi untuk air layak minum. 


\section{DAFTAR PUSTAKA}

1. Said, I. N., Teknologi Pengelolaan Air Minum: Teori dan Pengalaman Praktis. Badan Pengkajian dan Penerapan Teknologi. Jakarta Pusat. (2008).

2. Wakatsuki, T., Esumi, H., \& Omura, S. High performance and $\mathrm{N} \& \mathrm{P}$ removable on-site domestic wastewater treatment system by Multi-Soil-Layering method. Water Sci. Technol. 27(1): 31-40 (1993).

3. Attanandana, T., Saitthiti B., Thongpae S., Kritapirom S., Luanmanee, S., \& Wakatsuki, T., Multi-media-layering systems for food service wastewater treatment. Ecol. Eng., 15(1-2): 133-138 (2000).

4. Luanmanee, S., Boonsook, P., Attanandana, T., Saitthitii, B., Panichajakul, C., \& Wakasutki, T., Effect of Intermittent aeration regulation of a multi-soil-layering system on domestic wastewater treatment in Thailand, Ecol. Eng., 18(4): 415-428 (2002).

5. Latrach, L., Ouazzani, N., Masunaga, T., Hejjaj, A., Bouhoum, K., Mahi, M., \& Mandi, L., Domestic wastewater disinfection by combined treatment using multi-soillayering system and sand filters (MSL-SF): A laboratory pilot study. Ecol. Eng., 91: 294-301 (2016).

6. Ho. C. C., \& Wang, P. H., Efficiency of a Multi-Soil-Layering System on Wastewater Treatment Using Environment-Friendly Filter Materials, Int. J. Environ. Res. Public Health. 12(3): 3362-3380 (2015).

7. Zein, R., Suhaili, R., Novita, L., Mukhlis., Ningsih, S., Swesty, N., \& Novrian, H., Novel Two Stage Vertical Flow Biofilter System for Efficiency Treatment of Restaurant Wastewater. Res. J. Pharm. Biol. Chem. Sci., 7(5): 71-79 (2016).

8. Chen, X., Sato K., Wakatsuki T., \& Masunaga T., Effect of aeration and material composition in soil mixture block on the removal of colored substances and chemical oxygen demand in livestock wastewater using multi soil layering system, J. Soil Sci. Plant Nutr., 53(4): 509-516 (2007).

9. Munaf, E., \& Zein, R., The use of Rice Husk for Removal of Toxid Metals from Waste Water, Environ. Technol., 18(3): 359-362 (1997).

10. Sutrisno, T. C., \& Eny, S., Teknologi Penyedian air Bersih. Rineka Cipta. Jakarta. (1987). 